\title{
Implementation of Problem Based Learning among Nursing Students
}

\author{
Abdul Rahim Hamdan ${ }^{1}$, Chan Li Kwan ${ }^{1}$, Aqeel Khan ${ }^{1}$, Mohamed Najib Abdul Ghafar ${ }^{1} \&$ Ahmad Johari Sihes $^{1}$ \\ ${ }^{1}$ Faculty of Education, Universiti Teknologi Malaysia, Johor Bahru, Malaysia \\ Correspondence: Abdul Rahim Hamdan, Faculty of Education, Universiti Teknologi Malaysia (UTM), Skudai, \\ 81310 Johor Bahru, Malaysia. Tel: 60-7553-4261. E-mail: p-rahim@utm.my
}

Received: May 8, 2014 Accepted: June 12, 2014 Online Published: June 26, 2014

doi:10.5539/ies.v7n7p136 URL: http://dx.doi.org/10.5539/ies.v7n7p136

\begin{abstract}
Critical thinking and effective problem solving skills have been regarded as an important element and as an educational outcome in professional nursing. The purpose of this study is to examine the implementation of Problem Based Learning (PBL) among nursing students. More specifically, it compares pretest and post test scores of the implementation of PBL among third year students. The correlation between the levels of satisfaction of students toward PBL and the effectiveness of PBL were examined. Convenient sample methods were chosen and ninety four third year students participated from a private nursing college, Johor Bahru, Malaysia. Data of this study was analyzed using t-test. Findings indicated significant differences in overall scores of pretest and posttest among third year students. The result also demonstrated that the students' level of satisfaction towards PBL correlated with the effectiveness of PBL. From the finding, it has been concluded that implementation of PBL can be further developed through creative and innovative approach in the students' learning process.
\end{abstract}

Keywords: problem based learning, nursing, students

\section{Introduction}

The nurse carries out her function irrespective of race, religion, status, and respecting the culture of the various ethnic groups in Malaysian Society". As Malaysia is consists of three major ethnic groups in Malaysia: the ethnic Malays or bumiputera ( $65.1 \%$ of the population), the Chinese (26.0\% of the population), and the Indians ( $7.7 \%$ of the population), each with its respective religion, culture, and language (Shamsul, 2003, Cited in Khan et al., 2014; Verkuyten \& Khan, 2012). The nurse's in Malaysia working in multi-culture and multi-religious culture and need to deal all ethnicities (Khan et al., 2014).

The role of the nurse is to provide health care services in a wide variety of setting which includes health education, prevention of illness, promotion of health, care of the acute and chronically ill and rehabilitation. Barrow et al. (2002) reported that problem based learning within the nursing education has escalated in the recent year. Problem based learning aims to speed up the process and efficiency of clinical reasoning by placing learning in a functional context (Heliker, 1994). Gagne (1970) stated that in problem solving the learner combines the rules that he has learned previously to develop new higher-order rules which can be used to solve problems. Barrows et al. (1976) defined PBL as the learning that results from the process of working towards the understanding or resolution of a problem. The problem is encountered first in the learning process and serves as a focus or stimulus for the application of problem solving or reasoning, as well as for the search for the information or knowledge needed to understand the mechanisms responsible for the problem and how it might be resolved. PBL emerged as an innovative solution to the challenges that contemporary medical education faced with respect to the quality of student outcomes and preparation for practice. PBL is centered on three main principles: (a) The PBL process begins with problems rather than with exposition or prior learning of disciplinary knowledge, (b) it is a way of combining teaching and learning experiences with courses and curricula by using problems as the stimulus and focus for student activity, and (c) it is a student centered approach to learning (Barrows and Tamblyn, 1980; Charlin \& Mann, 1998; Ross, 1991). PBL is an innovative teaching method that has led to advancement in curriculum design that promotes specific learning strategies (Engel, 1991). PBL methods is supported by cognitive and constructivist educational theories, which can be described as dealing primarily with questions related to knowing - the perceptual aspects of learning, such as insights. Cognitivists see learning as an internal process involving memory, thinking, reflection, abstraction, motivation, and metacognition. According to Anderson and Elloumi (2005), cognitive psychology looks at 
learning from an information-processing point of view, where the learner uses different types of memory during learning. Sensations are received through the senses into the sensory store before processing occurs. Kalat (2002) added that the information persists in the sensory store for less than one second; if it is not transferred to working memory immediately, it is lost (p. 8). PBL is consistent with constructivism - the philosophical view that knowledge is not absolute but is constructed by learners based on their previous knowledge and worldview (Baker, 2000).

\subsection{Concepts related to Critical Thinking, Problem Solving and Problem Based Learning}

\subsubsection{Critical Thinking}

E. Bandman and B. Bandman (1988) defined critical thinking as the rational examination of ideas, inferences, assumptions, principle, arguments, conclusions, issues, statements, beliefs, and actions. Jones and Brown (1993) defined critical thinking as multidimensional way of thinking rather than an undimensional one. As such, critical thinking requires a skilful application of knowledge for the judgment and evaluation of complex problem situation. Jones and Brown (1993) also noted that critical thinking is interactive, process oriented, and rational, and that it is within this framework that knowledge is interpreted, assumptions are verified, hypotheses are generated, and justifications are made. Some educators claim that encouraging the students to ask questions, to consider different perspectives and alternatives, to examine problem and solutions in a new way, and too think beyond the first answer are important strategies for promoting critical thinking (Miller \& Malcom, 1990; Reilly \& Oermann, 1992). In fact, Oermann (1990) predicted that future teaching will emphasize fewer lectures and more experiential method such as PBL, simulations, and interactive videos to encourage students to think and consider alternate approaches to clinical problems (Khan, 2012).

Meyers (1988) identified five elements in teaching students critical thinking: begin the class with a problem or a controversial issue to promote student interactions, encourage reflection in student by using silence, arrange classroom space to enhance interaction, extend the class time whenever possible or needed, or create a friendly, nonthreatening environment. Hartley and Aukamp (1994) claimed that critical thinking ability is a dynamic attribute that can be improved by the nurse educators. Similarly, Cutler (1985) contended that critical thinking skills are teachable and learnable.

Brigham (1993) claimed that evaluation of the level of critical thinking skills of the nursing students has been a controversial issue. She suggested that, by designing test questioning that requires students to analyze, synthesize, look for evidence, recognize assumptions, hypothesize, and assess the situation, the level of critical thinking of students can evaluated.

\subsubsection{Problem Solving}

Woods (1987) described problem solving as a mental process by which the best answer or solution to an unknown is reached. As such, the problem situation has not been encountered before and past experiences cannot provide the solution. The knowledge and skills needed for problem solving depend on a domain-specific knowledge base; the ability to identify, locate, obtain, analyze, and evaluate requisite information; and interpersonal as well as communication skills (Woods, 1987). Dewey (1933) an advocate of inquiry based learning, recommended that real life situations or problems should be presented to the students, and then the students should be helped or discover the information required to solve the problems. Dewey (1933) stated that it is "fallacy" to assume that the passive provision of facts to the students would enable them to use these facts in solving problems. Gagne (1970) stated that in problem solving the learner combines the rules that he has learned previously to develop new higher-order rules which can be used to solve problems. In problem solving, the student is asked to discover the higher order principal without any specific help. Likewise, De Cecco and Crawford (1974) viewed problem solving as a form of principal learning in which lower order principles are applied to learning of higher order principles, which results in acquisition of new knowledge. Chamberlin (1965) suggested that the concept of problem solving as an educational method should be based on multiple working hypotheses; he believed that it is in this way that true problem solving methods of learning occur.

\subsubsection{Problem Based Learning}

Problem based learning emphasizes the principals of critical thinking and problem solving strategies. Problem based learning aims to speed up the process and efficiency of clinical reasoning by placing learning in a functional context (Heliker, 1994). Because PBL requires problem situations that are intellectually challenging to the students, it requires students' involvement in raising and discussing issues that pertain to the management of the problem. It helps students to think critically and solve problems. It helps students to be in charge of their own learning. It helps them to identify what they know and what they do not know. The teacher guides and facilitates 
the students' learning, and promotes interactions among students in order to enhance their problem solving abilities (Cited in Khan, 2013; Barrows \& Tamblyn, 1980).

\subsubsection{Problem-Based Learning in Nursing Education}

Barrows, Tamblyn, and Robyn (1976) introduced and defined PBL as the learning that results from the process of working towards the understanding or resolution of a problem. The problem is encountered first in the learning process and serves as a focus or stimulus for the application of problem solving or reasoning, as well as for the search for the information or knowledge needed to understand the mechanisms responsible for the problem and how it might be resolved. PBL emerged as an innovative solution to the challenges that contemporary medical education faced with respect to the quality of student outcomes and preparation for practice. Berkson (1993) stated, "Traditional medical education was increasingly perceived as dehumanizing, de-motivating, inefficient, and even ineffective" (p. 79).

The change from a subject-based curriculum to a PBL curriculum in nursing education resulted mainly from adopting the paradigm of medical education. Barrows (1985) noted that McMaster University School of Medicine set a precedent as a leader in adopting PBL in the curriculum because of the school's excessive course content, teaching restricted to lecturing, and poor congruence between educational and evaluation objectives.

PBL, one of the most popular developments in health professional education in the later part of the 20th century, was developed by Howard Barrows at McMaster University in Canada (Barrows et al., 1976), and most medical educators have adopted PBL as the educational and philosophical basis of their curricula (Harden et al., 1999). A PBL curriculum consists of subject integration within the sphere of professional practice situations. Learners acquire a broad base of knowledge through the process of progressive inquiry related to real nursing practice situations (Lambie, Maclean, \& McGuire, 1981).

PBL is centered on three main principles: (a) The PBL process begins with problems rather than with exposition or prior learning of disciplinary knowledge, (b) it is a way of combining teaching and learning experiences with courses and curricula by using problems as the stimulus and focus for student activity, and (c) it is a student centered approach to learning (Barrows \& Tamblyn, 1980; Charlin \& Mann, 1998; Ross, 1991). The theoretical underpinnings of PBL suggest that the closer the resemblance between the situations in which something is learned and the situation in which it will be applied, the more likely that a transfer of learning will occur. The elaboration of knowledge and provision of opportunities for elaboration are the main activities of PBL (Schmidt, 1983).

In nursing education, if outcomes are to be the qualifiers that define the curriculum design and ultimately the educational model for graduates, then the phase of defining outcomes within the curriculum is where the curriculum developers will ensure that the outcomes are clearly identified, defined, and integrated with the outcomes of the professional licensing body. Keating (2005) noted that this planning shapes the concepts embedded in the outcomes and competencies, which can be used as evaluation criteria for the program (Boland, 2005).

Educational method for promoting problem solving skills in student nurses is problem based learning. Therefore, ways of developing learner proficiency in problem solving is crucial and should occupy a substantial part of an educator's activity. It is the challenge of nursing education to explore ways to enhance student learning and clinical decision making. So, nurse educators have to investigate new teaching methods that promote active learning and increase critical thinking skills in students nurse. In the reality of a complex healthcare structure with changing society needs, it is important for students to learn how to access knowledge, synthesize the information, apply these data into practice and commit to life-long learning.

\subsection{Hypotheses}

The statement of hypotheses of research questions are as follow:

$\mathrm{H}_{\mathrm{o}}$ : There is no significant difference between scores on the pretest and posttest for the problem based learning method in Diploma Nursing Program.

$\mathrm{H}_{\mathrm{o} 2}$ : There is no significant correlation between the levels of satisfaction of students and the effectiveness of the PBL method in Diploma Nursing Program. 


\section{Method}

\subsection{Measures}

\subsubsection{Problem Based Learning Instrument}

This instrument was adapted from by Cutler (1985) and used for pretest and posttest purpose of measuring the implementation method of the PBL. This instrument consists of a description of a patient problem scenario that requires answer on a multiple-choice test for each question. The development of this instrument was based on the course objectives for the PBL sessions. This instrument was used as the pretest to assess the entry level of problem solving of the student prior to commencing the study. The same patient problem scenario was also used as the post test to measure the effectiveness of the PBL after completion of the PBL sessions.

\subsubsection{The PBL Attitudinal Instrument}

Measured the satisfaction of students and the effectiveness of the PBL method of instruction. The questionnaire comprises of 20 rank order items on a 5 point Likert-type scale representing "strongly agree" and 1 for "strongly disagree".

\subsection{Participants}

This study was conducted in the Diploma Nursing Student in a private college in the Johor state of Malaysia. Total 94 subjects participated, of which 72 male and 22 female students. Ages ranged from 20 to 25 years with the mean age of the participants being 21.07 years. The ethnicity of participants consists of 75 Malays and 19 Indians.

\subsection{Procedure}

The investigators obtained the permission to conduct this study from the University Technology Malaysia and KPJ Nursing College. Investigators obtained the consent to use the data for this study from each participant, so that students' awareness of being studied would not interfere with their normal responses and academic performances. The pretest was given at the beginning of the semester to the sample just prior to implementation of the first PBL session. The post test was given to the sample after completion of the 4 weeks of the PBL sessions. Each PBL session was of 2 hours duration. The pretest and posttest of each sample was reviewed and scored by the investigator. The students were informed that the pretest and posttest was not part of any grading system.

\subsection{Data Analysis}

Inferential statistics including the $\mathrm{t}$ test were used to test the difference between two independent group means (Evans, 1998).

\section{Results}

RQ1: Is there a statistically significant difference between scores on the pre test and post test for the problem based learning method in Diploma Nursing Program?

Table 1. T-Test for pre and post-test PBL

\begin{tabular}{cccccc}
\hline Scales & $\mathrm{N}$ & Mean & Standard Deviation & $\mathrm{p}$ \\
\hline Pre test & 94 & 7.40 & 2.31 & 0.00 \\
Post test & 94 & 10.93 & 1.95 & 0.00 \\
\hline
\end{tabular}

$\mathrm{p}$ is significant at 0.05 .

For the PBL pretest, the mean score was 7.40, with a standard deviation of 2.31 and a range of 3 to 11 . For the PBL posttest, the mean score was 10.93, with a standard deviation of 1.95 and a range of 5 to 14 . The scores showed that participants had scored considerably higher on the problem solving skills posttest than on the pretest. A Paired t-test was computed to determined significant differences between the pretest and posttest. Results showed significant for the pretest and posttest was $\mathrm{t}(93)=-13.70, \mathrm{p}<0.001$. As expected, a statistically significant is seen in the scores. 
RQ2: Is there a significant correlation between the levels of satisfaction of students and the effectiveness of the PBL method in Diploma Nursing Program?

Table 2. Satisfaction with effectiveness of PBL as a method

\begin{tabular}{ccc}
\hline Scales & Effectiveness & Satisfaction \\
\hline Effectiveness Pearson correlation & 1.00 & 0.97 \\
Sig (2 tailed) & & 0.00 \\
$\mathrm{~N}$ & 10 & 10 \\
Satisfaction Pearson correlation & 0.97 & 1.00 \\
Sig (2 tailed) & 0.00 & \\
$\mathrm{~N}$ & 10 & 10 \\
\hline
\end{tabular}

Correlation significant at the 0.01 level (2 tailed).

The results of these analyses are presented in Table 2, which shows the level of satisfaction with PBL seems to be correlated with the effectiveness of the PBL method. Therefore, it is concluded that the alternative hypothesis was accepted.

\section{Discussion}

The purpose of this study was to (a) compare initial knowledge acquisition from the use of problem based learning method in one group by using pretest and posttest, (b correlate between the levels of satisfaction of students and the effectiveness of the PBL method in diploma nursing program. Findings revealed positive experience on teaching method problem based learning in learning burn module. Nursing education and nursing administration can capitalize on these added values in the planning of teaching and learning activities in diploma nursing program. Hence, it implies that nursing education and nursing administration need to imply a new instructional methodology in nursing program.

Good thinking for nursing practice includes the ability to prioritize nursing action that will promote positive patient outcomes (Bechtel et al., 1999). Providing students with clinical scenarios via PBL requires that students apply knowledge to prioritize nursing action and make appropriate clinical decision.

In order for nursing students to be prepared to function as caring and competent professional nurses, they need a strong knowledge base and the ability to correlate this learning into clinical practice. Students need to have an understanding of how they think and make decisions. They need to leave the nursing program as graduates, who are independent thinker, self-directed learners with a commitment to life-long learning (Khan et al., 2014). Amos and White (1998) found that PBL enhanced students' critical thinking, learning how to learn, creativity in learning, research skills, and personal growth.

Current findings consistent with the previous findings (Walker et al., 2001; Wood, 2006; Yuan et al., 2011a) suggested that the PBL process has been adapted to move students gradually from teacher direction to taking responsibility for their learning. This has provided the opportunity for students to develop critical thinking, problem solving, information retrieval and evaluation skills, and group process skills over an 18-week period. Zubaidah (2005) also endorsed problem-based learning is a learning strategy which begins and centers on a clinical problem. It would be beneficial if this study replicated with larger population as sample size seemed to have an impact on the outcome of the result.

\section{References}

Anderson, T., \& Elloumi, F. (2005). Theory and Practice of Online Learning. Retrieved October 5, 2011, from http://www.cde.athabascau.ca/online_book

Andrews, M., \& Jones, P. R. (1996). Problem-Based Learning in an Undergraduate-Nursing Programme: A Case Study. Journal of Advanced Nursing, 23, 357-365. http://dx.doi.org/10.1111/j.1365-2648.1996.tb02679.x 
Baker, C. M. (2000). Problem-Based Learning for Nursing: Integrating Lessons from Other Disciplines with

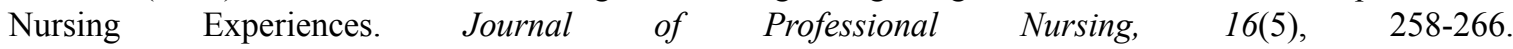
http://dx.doi.org/10.1053/jpnu.2000.9461

Bandman, E. L., \& Bandman, B. (1988). Critical Thinking in Nursing. Norwalk, C. A.: Appleton and Lange.

Barrow, E. J., Lyte, G., \& Butterwort, T. (2002). An Evaluation of Problem Based Learning in a Nursing Theory and Practice Module. Nurse Education in Practice, 2, 55-62. http://dx.doi.org/10.1054/nepr.2002.0043

Barrows, H. S. (1985). How To Design A Problem Based Learning Curriculum For The Preclinical Years. New York, N. Y.: Springer.

Barrows, H. S., \& Tamblyn, R. M. (1980). Problem Based Learning. New York, N. Y.: Springer.

Barrows, H. S., Tamblyn, R. M., \& Robyn, M. (1976). An Evaluation of Problem Based Learning in Small Groups Utilizing a Simulated Patient. Journal of Medical Education, 51(1), 52-54.

Bechtel, G. A., Davidhizar, R., \& Bradshaw, M. J. (1999). Problem-Based Learning in a Competency-Based World. Nurse Education Today, 19, 182-187. http://dx.doi.org/10.1016/S0260-6917(99)80003-3

Berkson, L. (1993). Problem-Based Learning: Have The Expectations Been Meet? Academic Medicine, 68(10), 79-88. http://dx.doi.org/10.1097/00001888-199310000-00053

Boland, D. L. (2005). Developing Curriculum: Frameworks, Outcomes, and Competence. In D. M. Billings, \& J. A. Halstead (Eds.), Teaching in Nursing: A Guide for Faculty (pp. 135-185). Philadelphia: W. B. Saunders.

Brigham, C. (1993). Nursing Education and Critical Thinking: Interplay of Content and Thinking. Holistic Nursing Practice, 7(3), 48-54.

Chamberlin, T. C. (1965). The Method of Multiple Working Hypotheses. Science, 148, 754-759. http://dx.doi.org/10.1126/science.148.3671.754

Charlin, B., \& Mann, K. (1998). Problem-Based Learning: Learning Strategies. Medical Teacher, 20(4), 1-16.

Cutler, P. (1985). Problem Solving In Clinical Medicine. Philadelphia, USA: Williams and Wilkins.

De Cecco, J. P., \& Crawford, W. R. (1974). The psychology of learning and instruction: Educational Psychology (2nd ed.). Englewood Cliffs, N. J.: Prentice-Hall.

Dewey, J. (1933). How we think: A restatement of the relation of reflective thinking to the educative process. Boston, M. A.: Health.

Engel, C. (1991). Not just a method but a way of learning. In D. Boud, \& G. Feletti (Eds.), The challenge of problem-based learning (pp. 23-33). New York: St. Martin's Press.

Gagne, R. M. (1970). The condition of learning (2nd ed.). New York, N. Y.: Holt, Rinehart and Winston.

Hartley, D., \& Aukamp, V. (1994). Critical thinking ability of nurse educators and nursing students. Journal of Nursing Education, 33(1), 34-45.

Heliker, D. (1994). Meeting the challenge of the curriculum revolution: Problem based learning in nursing education. Journal of Nursing Education, 33(1), 45-47.

Heliker, D. (1994). Meeting the challenge of the curriculum revolution: Problem based learning in nursing education. Journal of Nursing Education, 33(1), 45-47.

Jones, S. A., \& Brown, L. N. (1993). Alternative views on defining critical thinking through the nursing process. Holistic nursing Practice, 7(3), 71-76.

Kalat, J. W. (2002). Introduction to psychology. Pacific Grove, C. A.: Wadsworth-Thompson Learning.

Keating, S. B. (2005). Curriculum development and evaluation in nursing. New York, N. Y.: Lippincott Williams and Wilkins.

Khan, A. (2012). Sex Differences' in Educational Encouragement and Academic Achievement. Psychological Reports, 111(1), 149-155. http://dx.doi.org/10.2466/10.11.21.PR0.111.4.149-155

Khan, A. (2013). Predictors of Positive Psychological Strengths and Subjective Well-being among North Indian Adolescents: Role of Mentoring and Educational Encouragement. Social Indicators Research, 114(3), 1285-1293. http://dx.doi.org/10.1007/s11205-012-0202-x

Khan, A., Ahmad, R., Hamdan, R. A., \& Mustaffa, M. S. (2014). Educational Encouragement, Parenting styles, Gender and Ethnicity as Predictors of Academic Achievement among Special Education Children. 
International Education Studies, 7(2), 18-24. http://dx.doi.org/10.5539/ies.v7n2p18

Khan, A., Hamdan, R .A., Ahmad, R., \& Mustaffa, M. S. (2014). Predictors of Academic Achievement: Role of Gender, Self-Efficacy and Socio-Cultural Adjustment. Pensee Journal, 76(3), 406-410.

Lambie, A. T., Maclean, C. M. U., \& McGuire, R. J. (1981). The introduction of problem based learning projects into a clinical correlation course in the 1st year of the Edinburgh medical curriculum. Medical Education, 15(2), 209-215. http://dx.doi.org/10.1111/j.1365-2923.1981.tb02634.x

Meyers, C. (1988). Teaching students to think critically. San Francisco, USA: Jossey-Bass.

Miller, M. A., \& Malcolm, N. S. (1990). Critical thinking in the nursing curriculum. Nursing and Health Care, 11(2), 67-73.

Oermann, M. H. (1990). Research on teaching methods. Annual Review of Research in Nursing Education, 1-31.

Reilly, D. E., \& Oermann, M. H. (1992). Critical thinking in nursing education. New York, N. Y.: National League for Nursing.

Ross, B. (1991). Towards a framework for problem-based curricula. In D. Boud, \& G. I. Feletti (Eds.), The challenge of problem-based learning (pp. 33-41). New York: St. Martins Press.

Schmidt, H. G. (1983). Problem based learning: Rationale and description. Medical Education, 17, 11-16. http://dx.doi.org/10.1111/j.1365-2923.1983.tb01086.x

Shamsul, H. M. (2003). The Role of the State in Managing Ethnic Tensions in Malaysia. A Critical Discourse. American Behavioral Scientist, 47, 240-265. http://dx.doi.org/10.1177/0002764203256186

Verkuyten, M., \& Khan, A. (2012). Interethnic relations in Malaysia: Group identifications, indispensability and inclusive nationhood. Asian Journal of Social Psychology, 15, 132-139. http://dx.doi.org/10.1111/j.1467-839X.2012.01374.x

Walker, J., Bailey, S., Brasell-Brian, R., \& Gould, S. (2001). Evaluating a problem based learning course: An action research study. Contemporary Nurse: A Journal for the Australian Nursing Profession, 10, 30-38. http://dx.doi.org/10.5172/conu.10.1-2.30

Wood, S. (2006). Views of the effectiveness of problem-based learning. Nursing Times, 102(21), 34-38.

Woods, D. R. (1987). Problem based learning and problem solving. Sydney: Higher Education Research and Development.

Yuan, H., Williams, B. A., Yin, L., Liu, M., Fang, J., \& Pang, D. (2011a). Nursing students' views on the effectiveness of problem-based learning. Nurse Education Today, 31(6), 577-581. http://dx.doi.org/10.1016/j.nedt.2010.10.009

Zubaidah, S. (2005). Problem-based learning: Literature review. Singapore Nursing Journal, 32(4), 50-55.

\section{Copyrights}

Copyright for this article is retained by the author(s), with first publication rights granted to the journal.

This is an open-access article distributed under the terms and conditions of the Creative Commons Attribution license (http://creativecommons.org/licenses/by/3.0/). 